\title{
THE LIMITS OF PERCEPTUAL OBJECTIVITY IN INTERNATIONAL PEACE OBSERVATION*
}

\author{
Thomas M. Franck† and Kenneth H. Gold
}

\section{INTRODCCTION}

Methods of determining questions of fact have long been of concern to those interested in the legal process. Since the Second World War the use of military or civilian observers, international third-party peace-keepers, stationed along cease-fire lines separating hostile forces has become a major instrument of fact-finding in international disputes; yet no systematic attempt has been made to assess the role of these truce observers nor, indeed, to define scientifically, and perhaps, empirically, the possibilities and limitations of third-party decision-making in international disputes.

Preliminary study of the voluminous reports of cease-fire observation organizations suggests that the issues faced by the observers can be grouped into a number of recurrent typologica. This paper has not attempted such a systematic chronicling, since a few "typical" questions suffice for our purposes.

What kinds of factual issues have these "impartial" observers tried to solve? "The firing incident of 26 May, 1958 on Mount Scopus"1 provides an excellent illustration of the workings of the observers. The incident began when the Jordanian delegation to the Jordan-Israel Mixed Armistice Commission telephoned the United Nations Truce Supervisory Commission (UNTSO) to claim that Israelis located on Mount Scopus were firing on the Arab village of Issawiya. Within a few minutes, the UNTSO Chief of Staff's representative from Mount Scopus, Lieutenant-Colonel Flint, accompanied by one United Nations Military Observer (UNMO), proceeded to Issawiya while another UNMO observer set out for the Jewish sector of Mount Scopus to arrange a cease-fire and investigate the incident. While arranging for the cease-fire Colonel Flint was killed by a sniper's bullet. So were a number of Israelis. ${ }^{2}$

The Mount Scopus incident presented a number of issnes that had to be decided,

(C) 1968 by Thomas M. Franck.

+B.A. 1952, LL.B. 1953, University of British Columbia; LL.M. 1954, S.J.D. I959, Harvard University. Professor of Law and Director of the Center for International Studies, New York University. Author, Comparative Constrtutional Process (Cases and Materials in the Comparative Constitutional Process of Nation Building) (I968); The Structcre of IMpartiality (I968); co-author, Why FedersTIONS FAIL (1968).

¥B.S. I963, Babson Institute; LL.B. I967, LL.M. 1968, New York University. Research Assistant to Professor Thomas M. Franck and Editorial Associate at the Center for International Studies, New York University. Member of the New York bar.

${ }^{1}$ Report dated 7 June $195^{8}$ by the Chief of Staff of the United Nations Truce Supervision Organization in Palestine to the Secretary-General concerning the firing incident of 26 May 1958 on Mount Scopus, 13 U.N. SCOR, Supp. April-June 1958, at I, U.N. Doc. S/4030 (1958).

2Id. at 2 . 
all of them of a "factual" nature: Who was at fault? Who had fired the first shot? Where did the shot come from that killed Colonel Flint? Was Issawiya being used as a base by Arab troops before and during the incident?

There were other types of issues lurking in the background. Prior to the incident, two maps were in existence, one being relied upon by Israel, the other by Jordan. The maps conflicted as to the location of the demilitarized zone (DMZ). Which of the two maps should be controlling? What kinds of activities may rightfully be carried on in a DMZ? Is it closed to troops of each side? Is it closed to cultivation by civilians of each side: What patrolling responsibilities does the UN have to prevent infiltration through a DMZ? What, if any, preventive actions may be taken by either side if the UN fails to stop infiltration?

These would appear to be questions to which an impartial third-party decisionmaker could give answers, employing neutral, reciprocally-applicable principles. Yet these are the very questions the truce-observation organization did not feel itself empowered to answer. Being questions of "law" they were beyond its powers.

Instead, UNTSO investigated and answered the "factual" questions. As it happens, these involve the observers' direct sensory perception of a number of transient events, perceptions of a visual and audial nature.

Why was UNTSO authorized to answer questions of "fact" but not of "law"? It may be that we have to realize that "law-making" is a process involving the preferences of the decision-maker, however impartial, while we still believe that questions of "fact" when examined by an impartial decision-maker, can be objectively determined.

Tais paper hypothesizes that the distinction, at least so far as it encompasses "facts" based on perceptions of transitory sense-data, is misconceived. A neutral's finding of such a "fact," like a judge's finding of law, is not objective. That this is now scientifically provable shatters the myths which have supported impartial fact-finding processes just as, in an earlier part of this century, the insights of legal realists destroyed the myths of judicial objectivity. In both instances, however, the purpose is not to destroy valuable order-creating institutions but to make a more accurate estimate of the limits of their potential - what they can and cannot do-to help the institutions do better those things which are properly within their competence and to find other methods for resolving those types of problems which are not.

\section{II}

\section{The Neuro-Chemistry of Visual Perception}

It is not an easy thing for a lawyer, accustomed to separating sheep of truth from goats of falsehood, to accept that the events we see are not photographs of some reality "out there" but a series of events within our own bodies which have little objective relationship to the "picture" that forms in our heads. In the words of Dr. R. L. Gregory, 
There is a temptation, which must be avoided, to say that the eyes produce pictures in the brain. A picture in the brain suggests the need of some kind of internal eye to see it-but this would need a further eye to see its picture ... and so on in an endless regress of eyes and pictures. This is absurd. What the eyes do is to feed the brain with information coded into neural activity-chains of electrical impulses - which by their code and the patterns of brain activity, represent objects.... When we look at something, the pattern of neural activity represents the object and to the brain is the object. No internal picture is involved..$^{3}$

Thus, for example, colour has no objective existence in the sense (or code) in which we "picture" it. "[S]pectral colour, or hue, is light of a different frequency." In the "real" world, "out there," we do not have greens and reds, but only radiations of differing lengths and frequencies. The "picturing" of these radiation bands in terms of colour is something subjective we bring to the objective event. Consciousness, the perception of redness, for example, is defined by a leading British scientist as a "brain state" which in turn is a pattern of electrical impulses, "a certain structure of events in space-time" which, seen from the outside is, of course, not in the least red. $^{5}$

And none of us bring this subjectivity to the totality of such events occurring "out there," for none of us, for example, "see" radio waves, infra-red or ultra-violet light which are part of the same set of phenomena but beyond our visual perception. And more surprisingly, approximately one man in fifteen also cannot accurately perceive a difference even between red and green! ${ }^{6}$ Bronowski notes that colour-blindness does not appear to have come to the notice of science until $1777^{7}$ Other even less intrusive aspects of visual subjectivism are only now beginning to be explored.

How do we see?

The visual process appears to involve a complex interaction between mechanical, electrical and psychological fatcors. The eye, which, as we shall see, is "an integral part of the brain"8 both structurally and functionally, contains two kinds of cells in the retina which receive data-light waves-from "out there." These are called rods and cones. The cones function in daylight and give colour vision. The rods respond to very low levels of illumination and do not differentiate colours except in shades of grey. The rods are believed to be more primitive (in their lower levels of discrimination) but also more sensitive than the cones which give better detail and colour but only under conditions of more intense stimulation. The rods are thus believed to be closer to the primordial origins of the eye, or to lower rungs of the evolutionary ladder, being highly sensitive-the hawk's visual acuity is four times

\footnotetext{
- R. Gregory, Eye and Brain 7 (ig66).

Id. at 16.

- R. Brain, The Nature of Experience 64 (1959).

- J. Bronowsky, The Identity of MAN 53 (1965).

Id. at 52.

- R. Gregory, supra note 3 , at 46 .
} 
our own-b't distinguishing only those things, movement, and shadows in particular, which are essential to animal survival.

It appears that light hitting the cells of the retina causes a bleaching of its pigmentation, a chemical change, ${ }^{9}$ which, by an unexplained process, stimulates the optical nerve. Brightness is the basic rudiment of seeing. But even here, as in most aspects of visual perception, what is seen is not merely a carbon copy of an external event.

Brightness is not just a simple matter of the intensity of light striking the retina. The brightness given by a given intensity depends upon the state of adaptation of the eye, and also upon various complicated conditions determining the contrast of objects or patches of light. In other words, brightness is a function not only of the intensity of light falling on a given region of the retina at a certain time; but also of the intensity of the light that the retina has been subject to in the recent past, and of the intensities of light falling on other regions of the retina. ${ }^{20}$

In part, this is because the chemical bleaching process requires some time to reverse itself, to return to a state of equilibrium in readiness for the next stimulation. The state of disequilibrium can best be seen in its negative implications by the "afterimage" we see when we close our eyes or stare at a dark wall.

Similar subjective "fatigue" factors come into operation when we follow or fix moving objects or scenes in which objects are in movement. Some of these are muscular but others are electrical, as when the brain countermands certain clectrochem.cal impulses to take into account its own knowledge that it is a horse rather than a race-track which is in motion. The dizziness that follows after one has stopfed whirling is one evidence of the distortions which may result from daticountermanding continuing beyond the end of the circumstances in which it is needed for correct perception.

We still know very little of the steps which follow the original reception of light by the retinal rods and cones. Sir John Eccles states that there is

much neurophysiological evidence that a conscious experience arises only when there is some specific cerebral activity. For every experience it is believed that there is a specific spatio-temporal pattern of neuronal activity in the brain. Thus with perception the sequence of events is that some stimulus to the sense organ causes the discharge of impulses along afferent nerve-fibres to the brain, which, after various synaptic relays, eventually evoke specific spatio-temporal patterns of impulses in the neuronal network of the cerebral cortex. The transmission from sense organ to cerebral cortex is by a coded pattern of nerve impulses that is quite unlike the original stimulus to that organ, and the spatio-temporal pattern of neuronal activity that is evoked in the cerebral cortex would be again different. Yet as a consequence of these cerebral patterns of activity, I experience sensations (more properly the complex constructs called percepts) which in my private perceptual world are "projected" to somewhere outside .... .11

\footnotetext{
Id. at 49 .

${ }^{10} \mathrm{Id}$. at 74 .

${ }^{11} \mathrm{~J}$. ECCLES, The Brain ANd the UNity of CoNscious Experiesce 17-18 (1965).
} 
Eccles warns that the investigation of this sequence "is still at an extremely primitive stage." $" 12$

The process of visual perception has as its "basic component" the nerve cell or neuron which, as we have seen, generates an electric impulse which may be chemical in origin, as in the case of the bleaching described above. ${ }^{13}$ These electrical impulses, which also have chemical aspects, travel along branches of the neurons called axons, which are joined at switches or junctures (synapses) to other long, thin branches (dendrites) which carry impulses to nerve cells. The messages thus reach the cerebral cortex by a complex "series of relays of neurons which at all levels communicate with adjacent neurons."1t The relay is not, however, simply a system of communications-like the telephone switchboard to which it is sometimes compared -because, as the coded impulse-message moves along the system it is at each junction subject to a process of selection, rejection, or merger with other impulses.

In the cerebral cortex, there is a point-to-point topographical representation of the retina on its layers. Thus stimulation of one part of the retina activates a specific corresponding area of the visual part of the cortex ${ }^{15}$ where a response-circuit or complex is formed which is our perception: what we "see."

"What we see" is therefore a combination of many body-factors which are independent of, but act upon, the data received by the eye from the outside world. Some of these body factors are mechanical, some are neurological, some are psychological, and many are still unknown to us.

Bronowski, for example, tells us that "our senses doctor their messages before they reach the brain ..."16 and that

the eye does not send blank and unbiased signals to be interpreted in the brain .... $[\mathrm{T}]$ he rods and cones in the retina are connected together in complex groups... within the eye. The number of cross-links is huge, and their business is to integrate the individual sensations before they leave the eye. . . . And the single fiber is imperious; often, it does not so much inform the brain as instruct it, by sorting its messages in advance; and it does this most effectively by simply withholding information-by judging for itself what is irrelevant, and discarding it, without leave from the brain. ${ }^{17}$

Thus "the eye is not only an optical instrument; it is also an electrical network in which each unit integrates the darks and lights that it sees into messages, and decides which message should alert the attention and which need not." confirms that the retina

\footnotetext{
12 Id. at 18.

${ }^{13}$ J. Von Neumani, The Conputer and the Brats 40-4 I (1958).

${ }^{1 *}$ G. Wrburn, R. Pickford \& R. Hirst, Humas Sexses axd Perception 5, 7 (1964).

${ }^{15} \mathrm{Id}$. at 77 .

${ }^{16} \mathrm{~J}$. BRovowskl, supra note 6 , at 30 .

${ }^{17}$ Id. at $3 \mathrm{I}$.

${ }^{18} I d$. at 32 .
} 
is a sperialised part of the surface of the brain which has budded out and become sensitive: to light, while it retains typical brain cells lying between the receptors and the optic nerve ... . which greatly modify the electrical activity from the receptors themselves. Some of the data processing for perception takes place in the eye which is thus an integral part of the brain. ${ }^{19}$

From these discoveries Bronowski concludes that we have put an end "to the belief of philosophers that the brain receives a neutral picture of the world and sits in judgment over it."20

Von Neumann states, less romantically but to the same effect, that

pulses (which appear on the axons of a given neuron) are usually stimulated by other pulses that are impinging on the body of the neuron. This stimulation is, as a rule, conditional, i.e. only certain combinations and synchronisms of such primary pulses stimulate the secondary pulse in question-all others will fail to so stimulate. That is, the neuron is an organ which accepts and emits definite physical entities, the pulses. Upon receipt of pulses in certain combinations and synchronisms it will be stimulated to emit a pulse of its own, otherwise it will not emit. The rules wh.ch describe to which groups of pulses it will so respond are the rules that govern it as an active organ.1

Thus certain neurons will respond only when they receive two simultaneous incoming pulses from two other neurons. Other neurons may require as their minimum. input-price for stimulation not only a certain number of pulses from other neurons, but also that those pulses arrive in a certain spatial relation to each other.

That is, one may have to face situations in which there are, say, hundreds of synapses on a single nerve cell, and the combinations of stimulations on these that a.re effective (that generate a response pulse in the last-mentioned neuron) are characterized not only by their number but also by their coverage of certain special regions on that neuron (on its body or on its dendrite system), by the spatial relations of such regions to each other, and by even more complicated quantitative and geometrical relationships that might be relevant. ${ }^{22}$

What we have, therefore, is a complex of nerves reaching from the retina to the cerebral cortex-and each of them a small "brain" unto itself, each with criteria for accepting, rejecting or fusing and restructuring inputs. Indeed, since the decision as to this may in fact be a function of the synapses-the junctures of nerve cells, these even more numerous instrumentalities may be the basic "brains" of the perceptual system, employing a mathematic (rather than logical) system of thinking. ${ }^{23}$

What makes this important is not merely that it shows us the extent to which the transmission of visual data is, even at a physiological level, a process of selectivity

\footnotetext{
${ }^{10}$ R. GREGORY, supra note 3 , at $45-46$.

${ }^{20} \mathrm{~J}$. Bronowski, supra note 6 , at 32 .

21 J. Von Neumani, supra note 13, at $43-44$.

22 Id. at $54-55$.

${ }^{28}$ Id. at $79-80$.
} 
and of structuring and not merely a game of pass-it-on; it is, particularly, that the criteria employed in selecting and structuring, at every juncture, is a highly personal one and that no two persons have the same system of neural criteria. Thus, it is not only the colour-blind who see differently. Each of us sees differently from all the rest.

What gives each of our perceptive systems its uniqueness is just beginning to be explored. There is evidence that, to some extent, the criteria of the system are products of experience as well as of heredity. Von Neumann accepts that memory, in its physical embodiment, must have something to do with it. Thus the thresholds or stimulation criteria of each nerve cell over a period of time may be changed in response to experience. Frequent use of a nerve cell might have the result of lowering its criteria for the stimulation required to make it "fire." Memory thus becomes, according to this theory, a storing of experience in variable stimulation criteria. ${ }^{24}$ He adds that a

still more drastic embodiment of the same idea would be achieved by assuming that the very connections of the nerve cells, i.e., the distribution of conducting axons, vary with time. This would mean that the following state of things could exist. Conceivably, persistent disuse of an axon might make it ineffective for later use. On the other hand, very frequent (more than normal) use might give the connection that it represents a lower threshold (a facilitated stimulation criterion) over that particular path. In this case, again, certain parts of the nervous system would be variable in time and with previous history and would, thus, in and by themselves represent a memory. ${ }^{25}$

Von Neumann adds to these as-yet unproven hypotheses that "[a]nother form of memory, which is obviously present, is the genetic part of the body: the chromosomes and their constituent genes are clearly memory elements which by their state affect, and to a certain extent determine, the functioning of the entire system."26

Since our experiences and our genetic code are unique to each of us, and since these almost certainly have a direct physiological impact on the "machinery" through which the body interprets sensed data to arrive at its perceptions of "out there" it seems inevitable that those perceptions should be to a significant degree, unique to the perceiver. In addition, we appear to develop electric circuits in which stimulation of a part stimulates the whole "systems of nerve cells, which stimulate each other in various possible cyclical ways"27 much like a computer. These circuits, too, would appear to be "memories" built up by experience, although some circuits may also be genetically transmitted. But it is clear that, whatever their origin, they are manifestations of the unique, perceiving self. "[M]y visual perception," Eccles tells us, "is an interpretation of retinal data that in a lifetime of experience I have learned

\footnotetext{
21d. at 64 .

${ }^{25} 1 d$. at $64-65$.

"Id. at 65 .

${ }^{27}$ Id. at 66 .
} 
to accomplish, particularly in association both with sensory information provided by receptors in muscles, joints, skin and the vestibular apparatus, and with the central experience (.E willed effort."

Another perhaps less physiological way of looking at this is in terms of the learning process, which may or may not be understood in terms of "mutuallystimulating cyclical systems of nerves." In any event, while we know rather little about the internal or physiological nature of memory and learning, we do know rather a lot about its external or behavioural aspects. We know, in particular, "that, as a consequence of active or trial-and-error learning, the brain events evokcd by sensory information from the retina are interpreted so that they give a valid picture of the external world that is sensed by touch and movement. ..."29 In other words, we tend to see what experience teaches us we ought to expect to see.

For the most part this interaction of experience-data with sense data makes it possible for us to operate in a three-dimensional, populated world, by correcting sense-data which would mislead us in the light of what "we know is there." Yet, since behavioural experience, while to some extent universal, is also to some extent idiosyncratic, it too adds its part to "the uniqueness of the conscious experiences that each of us enjoys." ${ }^{\text {"30 }}$ Putting it another way, "[o]bjects are far more than patterns of stimulation: objects have pasts and futures; when we know its past or can guess its future, an object transcends experience and becomes an embodiment of knowledge and expectation"31 - but of $m y$ knowledge and my expectation. Thus the "seeing of an object ... involves knowledge of the object derived from previous experience"but o: $m y$ experience which becomes emboried in $m y$ knowledge. Therefore, the object I perceive becomes, to that extent, perceptively-speaking $m y$ object.

Psychology of visual perception goes so far as to say that "the senses do not give us a picture of the world directly; rather they provide evidence for checking hypotheses about what lies before us. Indeed, we may say that a perceived object $i s$ a hypothesis, suggested and tested by sensory data."32 But the hypothesis itself is inevitably and irreducibly a creative act of the individual self.

One way of comprehending this is through an examination of situations of conflicting sense-data. We have all watched one of those rotating spirals, sometimes found on phonograph-record labels, which seems to grow outward or to shrink, and at the same time to remain exactly the same size. Our brains know this to be impossible, and yet our eyes continue to send to the brain conflicting sets of data which the brain cannot reconcile. It must therefore choose one over the other, or suspend judgment, or reject both as "illusion." The brain, in this instance, has been

\footnotetext{
${ }^{28} \mathrm{~J}$. ECCLES, supra note $\mathrm{I} I$, at $\mathrm{II}$.

${ }^{20} \mathrm{Id}$. at 13.

${ }^{80} \mathrm{Id}$. at 36 .

s1 R. GREGORY, stipra note 3 , at 8 .

82 Id. at II-I2.
} 
described as being like a trial judge getting incompatible evidence from two witnesses and, for a time, accepting both. ${ }^{33}$

The work of psychologists in studying perception through the learning process is complemented by art historians. E. H. Gombrich's justly celebrated study, Art and Illusion, ${ }^{34}$ adopts the "searchlight theory" of perception of K. R. Popper ${ }^{35}$ which emphasizes the "activity of the living organism that never ceases probing and testing its environment" ${ }^{\prime 36}$ and shifts attention away from the approach-Popper calls it the "bucket theory of the mind"37-which emphasizes the stimulus rather than the organism's response to it. When I answer such a simple question as: "how did she look?" I am drawing on visual sense data, of course, but also, and perhaps preponderantly on a complex of perceptive (neural) factors inherent in me; acquired attitudes towards persons, towards women, towards her; as well as to her perception of herself as perceived by me (her subjectivity); and finally to factors external both to her and to me (what she was doing, where she was standing, how the light illuminated her, and so on.)

It is appropriate that art history should come to the aid of psychology in the study of perception. For, in no other field is it more clear that what we see is in large part what we bring from the rich storehouse of our experience to the relatively austere visual stimulus of the existential moments that the artist captures for us. A painting is a stylized code for reality which our experience lets us break, thereby making a two-dimensional representation achieved by use of line and colour "come alive" in our mind's eye. Size, distance, depth, dimension-all these we bring to the artist. All the artist brings to us is an ability to call us to draw from our experience the beauty or horror which he knows to be there, even when we ourselves may have forgotten or denied it, and to do so at a command to us written in paint on canvas.

Another simple way to test the impact of what we know on what we see is to look at our two hands held in front of us-one at arm's length, the other at half the distance and to the left. The two hands will of course look about the same size, confirming what we know. But move the nearer hand directly in front of the line of vision of the further, and it will look twice as large, which is the way the sensedata registers on the retina. As long as the hands are separate, the mind can correct the sense data's proportions. When the hands are brought to overlap, their comparative size as sense-data can no longer so readily be overruled by a puzzled mind which nevertheless "knows better." To psychologists the mind's corrective process is known as "constancy scaling." 38

\footnotetext{
${ }^{33}$ Id. at I08.

a E. Gombrich, ARt ANd Illusion (Ig6o).

${ }^{38}$ Cf. 2 K. Popper, The Open Society a.d Its Exemies 260-62, 361 (4th ed. I963).

${ }^{30} \mathrm{E}$. GoMbrich, supra note 34 , at 28.

${ }^{34} 2$ K. Popper, The Open Society and Its Enemies $214,260,36$ I (4th ed. 1963).

${ }^{38} R$. Gregorr, supra note 3 , at I5I, 152.
} 
If the mind draws on experience to achieve "constancy scaling" it is not surprising th.t the eye cells can (and, in their own way, do) perform similar feats. We know: of course, that the pupils of the eye expand and contract in direct relation to the amount of light entering. But when one light of $\mathrm{X}$ intensity is lit in a dark room and thereafter an additional, dimmer light of $Y$ intensity is also lit, the pupil's contraction will be responsive not to the light intensity of $X+Y$ but rather to $\frac{X+Y}{2}$, which is to say, the average between the two intensities!

Finally, the cooperative work of anthropologists has enriched perception-psychology by providing us with studies of "primitive" people living in dense forests who do not have the opportunity to experience distant objects over unbroken vistas. When such persons were taken out of their forest home to open plains, they saw remote objects not as distant but as small. People like ourselves, who live our lives on the ground, experience similar failures of the "constancy scaling" mechanism when we look down at objects from a height. On the other hand, persons who spend much of their time in high buildings report seeing people below without the sense of their being toy miniatures. ${ }^{39}$ This, too, tells us much about the role of previous experience and trial-and-error learning in perception. ${ }^{40}$ It is, incidentally, worth noting that there is no evidence that these corrective mechanisms by which we restructure what we see by what we know exist in any other animals except possibly the monkey. ${ }^{41}$ It is also s.gnificant that the one area in which we seem unable to make such a perceptive readjustment is where there is a conflict in time (as opposed to space, where we do learn to make adjustments) between what we see and what we know.

To the subjective aspects of perception, then, we must add another: what we see is in part a function of acculturation. Different societies learn to adjust to visual sensedata in different ways. This need not even be tested by examining forest people or cliff-dwellers. It is sufficient to leaf through a book on the history of art, such as that of Frofessor Gombrich, and see the totally different ways in which different civilizations learned to code reality. The Chinese, early Egyptian or renaissance art seems to us as "unreal" today as French impressionism would strike an ancient Mesopotamian-because each society's artists use different artistic codes to represent or suggest reality and each society, reciprocally, learns to be called to that reality by that system of representation, to do its "constancy scaling" in accordance with a datacode particular to itself. Thus most of the members of one society in one age cannot perceive the art of another age as anything but "unreal."

Before leaving this aspect of the subjectivity of visual perception it must be stated that an increasing number of psychologists are willing to entertain heredity-theories

\footnotetext{
${ }^{39} I d$. at $\mathrm{I} 6 \mathrm{r}-62$.

10 Id. at 180 .

41 Id. at 216.

${ }^{22}$ More exactly, there is usually a lag between the invention of a new artistic style and the time when the society learns to "sec" it as "real."
} 
to explain a part of the subjective self brought to the interpretation of sense-data, just as neurologists and physiologists are giving greater credence to genetic factors in neural stimulation-criteria. Professor Gregory in his study of the psychology of perception states that

[t] he visual brain has its own logic and preferences which are not understood cortically. Some objects are beautiful, others ugly; but we have no idea, for all the theories which have been put forward, why this should be so. The answer lies a long way back in the history of the visual part of the brain, and is lost to the new mechanisms which give our intellectual view of the world. ${ }^{43}$

This hypothesis is, of course, still an open and controversial one. But his conclusion is not: non-visual characteristics (of the individual) affect how objects are seen.

\section{III}

ConcLusion

In the truce observer context, those questions of fact which are concerned with sensory perception of transient events or conditions are not appropriate for impartial third-party decision-making. The reason these issues are inappropriate is that they cannot be answered objectively because even the most neutral of observers brings to his sensory-perceptive process a subjectivity which is the greater for being hidden deep in the sensory-perceptive process where reason and conscious argument do not enter. Such perceptions are really like opinions, but the more tenacious and irreversible because they come to our consciousness disguised as objective truth.

There are, however, other ways to achieve order in a dispute such as that of May 26, 1958, which do not involve attempts to ascertain the unascertainable. The objectives of UNTSO were twofold: to prevent recurrence of the incident, and to compensate the victims.

There is no need for findings of "fact" in order to achieve these ends. Recurrence can best be prevented by prospective administrative arrangements. These require the good will of the parties, which is only diminished by attempts to fix "guilt" for prior occurrences. As to compensation, it would be reasonable to anticipate that a certain number of such incidents would occur in the course of any truce, that it would be troublesome and probably impossible to assign fault, and therefore the parties agreeing to the establishment of the truce regime might also agree to establish a joint compensation fund. The role of the truce observer would then be to assess actual damage done, rather than fixing "fault." The fund would then provide compensation while administrative efforts were bent toward preventing the incident's repetition.

\footnotetext{
4R. GREgory, supra note 3, at 224 .
} 


\section{An Index to Modern Legal Problems}

On each of the following topics, Law and Contemporary Problems has published or will publish a symposium dealing with the legal, economic, administrative, and other social-science aspects of the subject. The date indicates the year of publication.

\begin{tabular}{|c|c|c|c|}
\hline Academic Freedom & 1963 & Government Contractst & 1964 \\
\hline Administrative Regulation & 1961 & Government Tort Liability & 1942 \\
\hline African Law & 1962 & Hemispheric Trade & 1941 \\
\hline Agricultural Adjustment in the South & 1934 & Home Financing & 1938 \\
\hline Air Cargo & 1950 & Housing & 1947 \\
\hline Air Pollution & 1968 & Housing: Perspectives and Problems & 1957 \\
\hline Alcoholic Beverage Control & 1940 & Housing: The Federal Role & 1967 \\
\hline Alimory & 1939 & Immigration & 1956 \\
\hline Antipoverty Programs & 1966 & Instalment Selling & 1935 \\
\hline Antitrust Laws and Single-Firm & & Institutional Inrestments & 1952 \\
\hline Conjuet & 1965 & International Commodity Agreements & $196 i$ \\
\hline Atomic Powe1 Derelopment & 1956 & International Control of Propaganda & 1966 \\
\hline Aviation Transport & 1946 & International Human Rights $\dagger^{-}$ & 1949 \\
\hline Banking $f$ & 1967 & International Trade Barriers & 1946 \\
\hline Children of Divorced Parents & 1944 & Interterritorial Froight Rates & 1947 \\
\hline Close Corporation & 1953 & Investment of Trust Funds & 1938 \\
\hline Collection of Real Property Tases & 1936 & Jurimetries & 1963 \\
\hline Oollective Bargaining Under the & & Labor Disputo Settlement & 1947 \\
\hline Wagner Act & 1938 & Labor in Wartime & 1942 \\
\hline Combating the Loan Shark & 1941 & Land Planning in a Democracy & 1955 \\
\hline Commercial Arbitrationt & 1952 & Legislative Reapportionment & 1952 \\
\hline Commercial Codef & 1951 & Literary and Artistic Products and & \\
\hline Corsumption Taxes & 1941 & Copyright Problems & 1954 \\
\hline Cooperatires & 1948 & Loan Shark Problem Today & 1954 \\
\hline Co:rection of Youtheul Offenders & 1942 & Low-Cost Housing and Slum Clearance & 1934 \\
\hline Crime and Correction & 1958 & Medical Care & 1939 \\
\hline Delirered Pricing & 1950 & Medical Progress and the Law & 1967 \\
\hline Divorce: A Re-examination of & 1953 & Migratory Dirorce & 1935 \\
\hline $\begin{array}{l}\text { Basic Concepts } \\
\text { Electoral Processt }\end{array}$ & 1962 & Narcotics & 1957 \\
\hline $\begin{array}{l}\text { Electoral Processt } \\
\text { Emergency Price Control Act }\end{array}$ & 1942 & Nationalization of British Industries & 1951 \\
\hline $\begin{array}{l}\text { Emergency Price Control Act } \\
\text { Enemy Property }\end{array}$ & $19 \pm 5$ & New Look in Corporation Law & 1958 \\
\hline European Regional Communities & 1961 & New Trends in the Conflict of Laws & 1963 \\
\hline Excess Profits Taxation & 1943 & Obscenity and the Arts & 1955 \\
\hline Expert Testimony & 1935 & Old Age Security and Welfare Titles & \\
\hline Farm Tenancy Legislation & 1937 & of the Social Security Act & 1936 \\
\hline Federal Courts & 1948 & Patent System $t$ &, 1948 \\
\hline Federal Employers' Liabilite Actf & 1953 & Population Control & 1960 \\
\hline Federal Income and Estate Taxation & 1940 & Presidential Office & 1956 \\
\hline Federal Powers Over Crime & 1994 & Preventive Larr of Conflicts & 1956 \\
\hline Financial Protection for the Mutor & & Price Control in a Cold WTar & 1954 \\
\hline Accident Victin & 1936 & Price Discrimination and & \\
\hline Financing Small iusiness & 1945 & Price Cutting & 1937 \\
\hline Food, Drug, and Cosmetic Legislation & 1939 & Privact & 1966 \\
\hline Gorernment Marketing Barriers & 1941 & Prirate Insurance & 1950 \\
\hline ed in tro parts, priced sepsiatels. & & Problems of the Aging & 1962 \\
\hline
\end{tabular}

